\title{
SISTEM PENYIRAMAN PESTISIDA OTOMATIS MENGGUNAKAN ARDUINO UNO DAN GSM SHEILD SIM 800L
}

\author{
Gusrio Tendra \\ AMIK “Tri Dharma” Pekanbaru \\ Jl. Jend Sudirman No. 68 D Pelita Pantai, Pekanbaru, Riau \\ e-mail : gusriotendra@amiktridharmapku.ac.id
}

\begin{abstract}
ABSTRAK
Untuk menjaga kesegaran dan kwalitas tanaman kita maka perlu dijaga baik dari penyiraman air maupun pupuknya. Agar tidak banyak hama yang menempel pada tanaman kita maka perlu diberikan pupuk anti hama atau sering kita sebut pestisida, tetapi petani harus melakukannya secara manual dengan menyemprotkan menggunakan penymeprot manual yang harus memompa terlebih dahulu. Untuk memudahkan para petani dalam menjaga kesuburan tanaman mereka dan terhindar dari hamahama perusak tanaman maka dirancang suatu alat penyiraman pestisida secara otomatis yang berkerja sesuai jadwal yang sudah ditentukan didalam program.
\end{abstract}

Kata Kunci : Arduino UNO, RTC DS1307, GSM Sheild SIM 800L, Motor Pompa

\begin{abstract}
To maintain the freshness and quality of our plants, it is necessary to protect them from sprinkling water and fertilizers. So that there are not many pests sticking to our plants, it is necessary to apply antipest fertilizers or we often call them pesticides, but farmers have to do it manually by spraying using manual sprays that have to pump first. To make it easier for farmers to maintain the fertility of their crops and avoid pests that destroy crops, an automatic pesticide sprinkler is designed that works according to the schedule specified in the program.
\end{abstract}

Keywords : Arduino UNO, RTC DS1307, GSM Sheild SIM 800L, Motor Pump

\section{PENDAHULUAN}

Kemajuan teknologi informasi dan komunikasi di dunia kini berkembang sangat cepat. Sekarang banyak alat-alat elektronik yang berbasis teknologi yang dapat mempermudah kerja manusia, salah satunya adalah komputer. Saat ini komputer bukan hanya digunakan untuk mengelolah data dan informasi tetapi komputer juga bisa melakukan kendali melalui sebuah chip yang bisa mengontrol alat elekronik lainnya. Salain itu, kini banyak perusahaan elekronik berlomba-lomba dalam mengembangkan alat kendali yang menggunakan teknologi canggih, salah satunya pengembangan modul GSM Shield yang bisa memberikan pemberitahuan kepada user melalui SMS.

Dalam dunia pertanian banyak hal yang harus diperhatikan dalam menjaga kualitas hasil pertanian agar tetap segar dan baik. Banyak petani yang gagal dalam hasil taninya karena kekurangan air dan kurang memperhatikan pupuk atau pembunuh hama seperti pestisida untuk kesuburan daun khususnya bagi pertanian yang menggunakan rumah kaca atau di dalam ruangan. Tidak sedikit petani yang lupa dalam memberi pupuk atau melakukan penyemprotan pestisida sehingga mengakibatkan pengaruh besar pada daun dan tanaman tersebut. Secara harfiah, pestisida berarti pembunuh hama (pest: hama dan cide: membunuh). Senyawa kimia banyak digunakan dalam bidang pertanian antara lain sebagai pupuk tanaman dan pestisida (Fajriani, dkk, 2019).

Petani dalam mengolah lahan membutuhkan pestisida untuk memberantas hama dan gulma. Namun di sisi lain pestisida dapat membahayakan kesehatan diri petani, konsumen serta lingkungan (Istianah, dan Yuniastuti, 2017). 
IN F ORMA T IK A

Jurnal Informatika, Manajemen dan Komputer, Vol. 12, No. 2, Desember 2020

eISSN : 2580-3042

pISSN : 1979-0694

Pada penelitian sebelumnya mengenai perancangan prototype drone penyemprot peptisida untuk pertanian padi secara otomatis, Perancangan prototype drone untuk mengangkut tabung pestisida berhasil dilakukan dengan menggunakan drone tipe hexacopter dan menggunakan motor brushless 980KV serta propeller ukuran $10 \times 4,7-i n c h$, total berat drone keseluruhan yang mampu diangkat yaitu $2,5 \mathrm{~kg}$. Proses penyemprotan telah dapat dilakukan secara otomatis dengan memanfaatkan sensor jarak (ultrasonic) yang pada penelitian ini rentang jarak deteksi yang diatur yaitu $\leq 320 \mathrm{~cm}$ (Hidayat, dkk, 2019).

Pada penelitian sebelumnya juga telah dibangun sistem penyiraman otomatis untuk tanaman berbasis aruduino dan kelembaban tanah, dimana perancangan prototipe otomatisasi pompa air motor AC bertenaga surya berbasis arduino uno dan kelembaban tanah berhasil dilakukan, dan dapat bekerja sesuai yang di inginkan Indikator keberhasilan alat ini adalah system dapat memberikan respon keluaran berupa kenaikan dan penurunan kelembaban media tanam, dan system akan memberikan respon terhadap parameter batas bawah dan parameter batas atas dengan menghidupkan atau mematikan pompa air melalui relay (Alam, dkk, 2018).

Berdasarkan penjelasan di atas, penulis mendapat gagasan untuk perancangan alat sistem penyiraman pestisida pada tanaman menggunakan arduino dan GSM Shield dimana alat ini dapat mengontrol penyiraman cairan pestisida berdasarkan jadwal yang di tentukan secara otomatis dan juga memberi.

\section{METODOLOGI PENELITIAN}

Pada penelitian ini penulis menggunakan metode pengembangan perangkat lunak untuk mengembangkan Sistem Penyiram Peptisada Otomatis ini, adapun metode yang digunakan adalah SDLC Waterfall. SDLC atau Software Development Life Cycle adalah proses mengembangkan atau mengubah suatu sistem perangkat lunak dengan menggunakan modelmodel dan metodologi yang digunakan orang untuk mengembangkan sistem-sistem perangkat lunak sebelumnya, berdasarkan best practice atau cara-cara yang sudah teruji baik (Firmansyah, dan Udi, 2018). Gambar 1 dibawah ini merupakan bagan dari SDLC yang terdiri atas tujuh tahap pengembangan yang digunakan pada proses penelitian untuk membangun dan mengembangkan Sistem Penyiram Peptisada

Otomatis Menggunakan Arduino UNO dan GSM Shield.

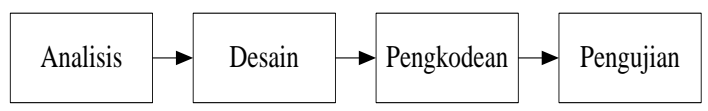

Gambar 1. Metode Pengembangan Sistem

Dalam tahapan analisis penulis menganalisa kebutuhan data baik cara kerja, bentuk penyiraman yang tepat, waktu yang dibutuhkan dan banyaknya peptisida yang dapat disiramkan dalam kurun waktu tertentu. Dalam tahapan desain penulis melakukan desain sistem dalam bentuk desain secara umum dengan menggunakan context diagram, data flow diagram, dan flowchart diagram sebelum melakukan penggkodean. Selain desain umum penuis juga menggambarkan sketsa yang akan digunakan untuk menggambarkan cara kerja alat yang akan dibuat. Setelah desain selesai dilakukan maka tahap selanjutnya ialah dengan melakukan pengkodean terhadap Arduino UNO dengan menggunakan bahasa pemrograman $\mathrm{C}$, dan menghubungkan dengan module GSM Shield yang berfungsi untuk menerima dan mengirim pesan sebagai acuan dalam pelakukan proses penyiraman. Setelah pengkodean selesai barulah dilakukan pengujian untuk mengetahui apakah sistem yang dibangun sesuai dengan yang diharapkan.

\section{HASIL DAN PEMBAHASAN}

Pada penelitian ini penulis menggunakan Arduino UNO sebagai perangkat yang digunakan untuk melakukan control terhadap waktu penyiraman peptisida. Arduino Merupakan papan elektronik berbasis mikrokontroller ATMega yang memenuhi sistem minimum mikrokontroller agar dapat bekerja secara mandiri (standalone controller). Komponen utama didalam papan Arduinoadalah sebuah mikrokontroler 8 bit dengan merk ATMega yang dibuat oleh Atmel corporation. Berbagai papan Arduino menggunakan tipe Atmega yang berbeda-beda tergantung dari spesifikasinya, sebagai contoh Arduino Uno menggunakan ATmega328 sedangkan Arduino Mega 2560 yang lebih canggih menggunakan ATmega2560. Dalam penelitian ini penulis menggunakan papan mikrokontroller arduino tipe arduino uno yang menggunakan chip Atmega 328 (Bahrin, 2017).

Dengan menggunakan inputan dari pesan singkat yang dikirim melalui perangkat smartphone melalui SMS, Arduino akan 
I N F O R M A I I A

Jurnal Informatika, Manajemen dan Komputer, Vol. 12, No. 2, Desember 2020

eISSN : 2580-3042

pISSN : 1979-0694

mengendalikan mesin pompa air yang bertugas untuk menyiram tanaman dengan peptisada. Teknologi GSM yang penuis pakai menggunakan frekuensi $800 \mathrm{MHz}$. Modul GSM SIM 800L yang akan digunakan merupakan perangkat yang menggantikan fungsi handphone disamping itu perangkat ini berbentuk kecil, ringan dan mudah untuk mengintegrasikan,konsumsi daya rendah (Fauzi, dkk, 2018).

\section{a. Context Diagram}

Context Diagram digunakan untuk memudahkan proses penganalisaan terhadap sistem yang dirancang secara keseluruhan. Context Diagram berfungsi sebagai sebuah media yang terdiri dari suatu proses dan beberapa buah external entity. Context Diagram (CD) memperlihatkan sistem yang dirancang secara keseluruhan, semua external entity harus digambarkan sedemikian rupa, sehingga terlihat data yang mengalir pada input-proses-output. Adapun Context Diagram dari alat yang dibuat dapat dilihat pada gambar 2 berikut

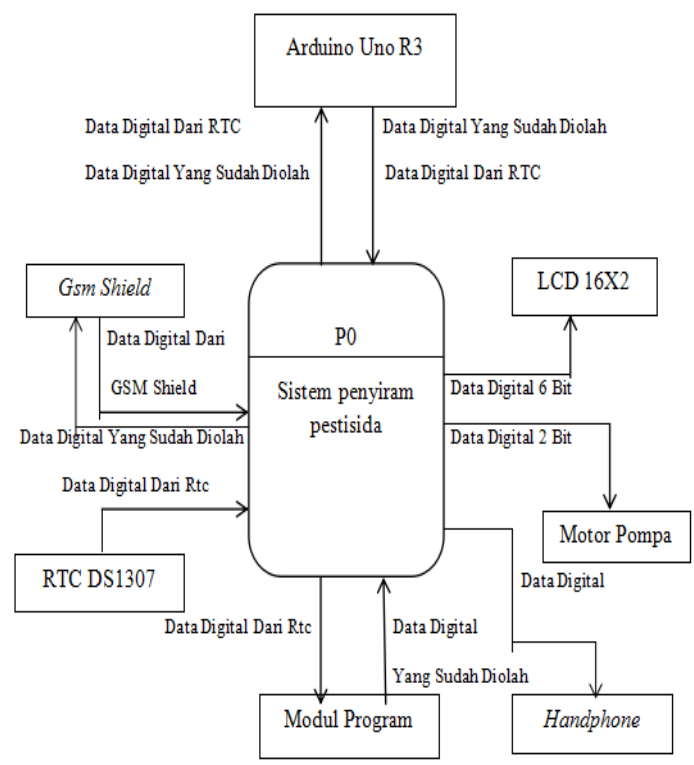

Gambar 2. Context Diagram

\section{b. Data Flow Diagram (DFD)}

Untuk memberikan penjelasan lebih terperinci tentang sistem yang sedang dibangun, bisa dilihat pada data flow diagram yang akan dijelaskan secara terprinci. Dimana didalam data flow diagram ini jumlah entitynya harus sama dengan jumlah entity yang ada pada context diagram. Adapun proses tersebut dapat dilihat pada gambar 3 berikut :

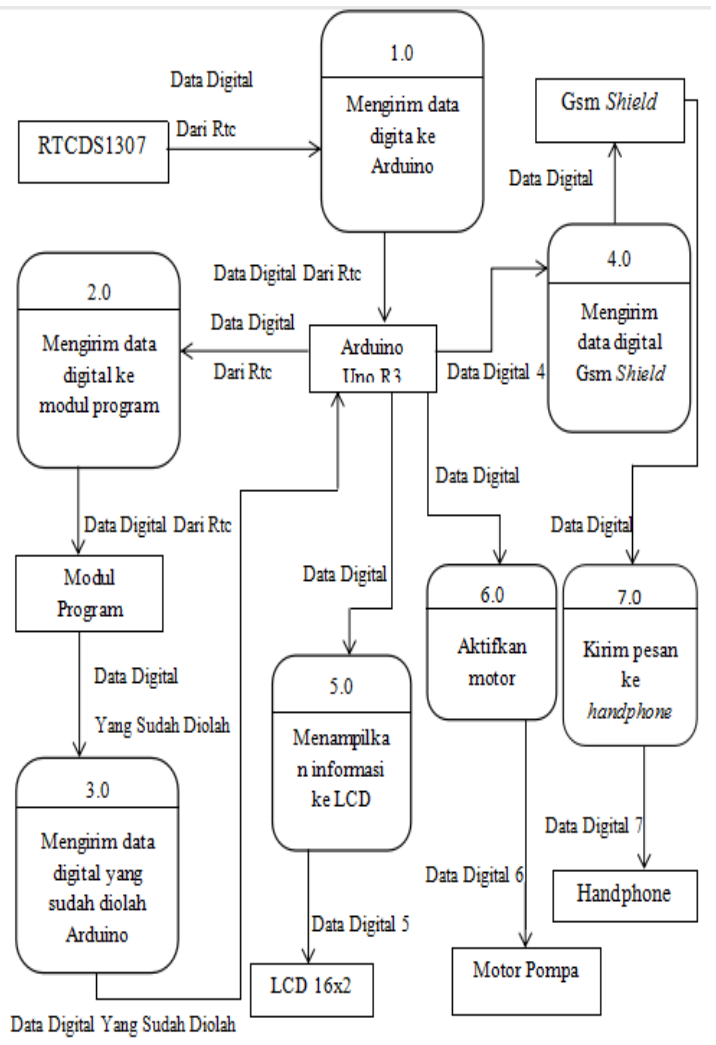

Gambar 3. Data Flow Diagram

\section{c. Flowchart Diagram}

Flowchart digunakan terutama untuk alat bantu komunikasi dan untuk dokumentasi. flowchart juga merupakan urutan-urutan langkah kerja suatu proses yang digambarkan dengan menggunakan simbol-simbol yang disusun secara sistematis. Agar modul program yang dirancang memiliki struktur dengan kualitas yang baik dan mudah dimengerti. Logika dasar gambaran pada penilisan ini adalah menggunakan flowchart. Berikut adalah gambar dari flowchart yang ada dalam sistem yang sedang dirancang dapat dilihat pada gambar 4 dibawah ini : 
INFORMA TIK

Jurnal Informatika, Manajemen dan Komputer, Vol. 12, No. 2, Desember 2020

eISSN : 2580-3042

pISSN : 1979-0694

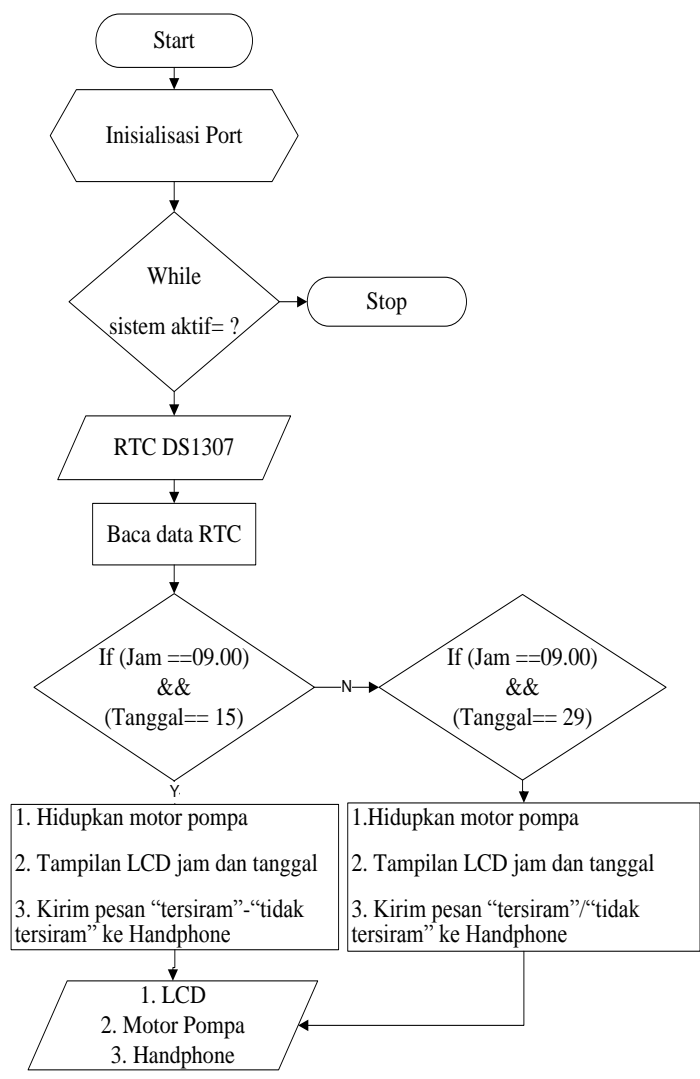

Gambar 4. Flowchart Diagram

\section{d. Rancangan Fisik}

Rancangan fisik sistem ini dapat dikelompokan dalam beberapa bagian yaitu :

1. Arduino Uno R3

2. Power Supplay atau catu daya

3. LCD $16 \times 2$

4. Motor Pompa DC $12 \mathrm{~V} 9$ watt

5. RTC DS1307

6. Gsm Shield Sim 800L

Sketsa sistem penyiram pestisida dapat dilihat pada pada gambar 4 dibawah ini.

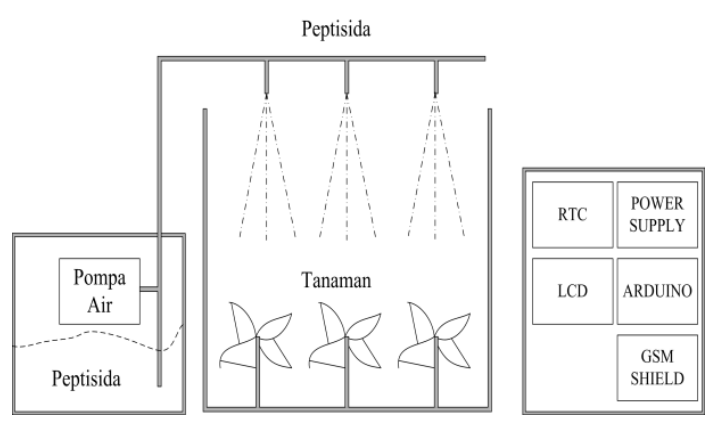

Gambar 5. Rancangan Sistem Penyiram Pestisida

\section{e. Pengujian Sistem}

Sistem penyiram pestisida menggunakan arduino dan Gsm Shield yang sudah dirancang pada bab sebelumnya telah di implementasikan pada sebuah alat prototipe. Cara kerja dan langkahlangkah menggunakannya adalah sebagai berikut:

1. Pasangkan kabel power ke sumber arus untuk mengaktifkan sistem. Cara menghubungkan kabel power dapat dilihat pada gambar 5 berikut :

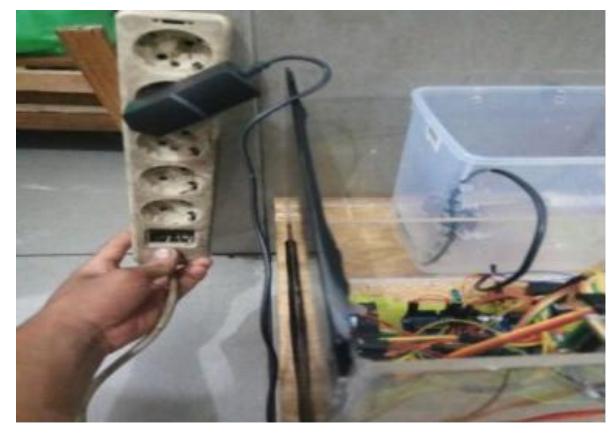

Gambar 6. Menghubungkan Kabel Power

2. Kemudian sistem akan aktif, sistem aktif dapat ditandai dengan tambilnya jam di layar LCD. Berikut adalah gambar dari sistem yang telah aktif dapat dilihat pada gambar 6 dibawah ini :

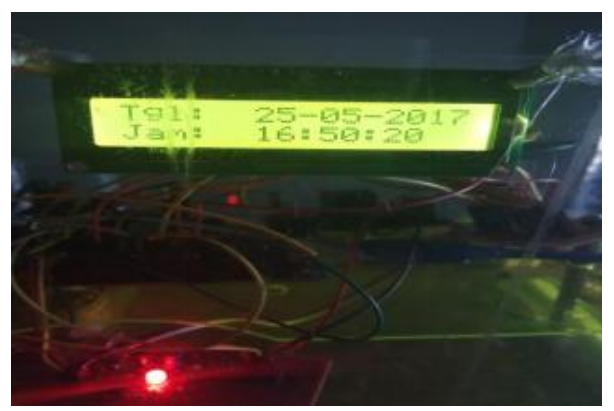

Gambar 7. Tampilan Jam Pada LCD

3. Apabila sistem telah aktif maka sistem akan menunggu untuk melakukan kerja berupa menyiram pestisida ketanaman sesuai waktu yang sudah diset pada sistem.

Contoh jika tanggal 7-6-2020 jam 13.09 maka pompa akan aktif. Berikut adalah gambar saat pompa melakukan penyiraman pestisida dapat dilihat pada gambar 7 dibawah ini : 
INFORM T IKA

Jurnal Informatika, Manajemen dan Komputer, Vol. 12, No. 2, Desember 2020

eISSN : 2580-3042

pISSN : 1979-0694

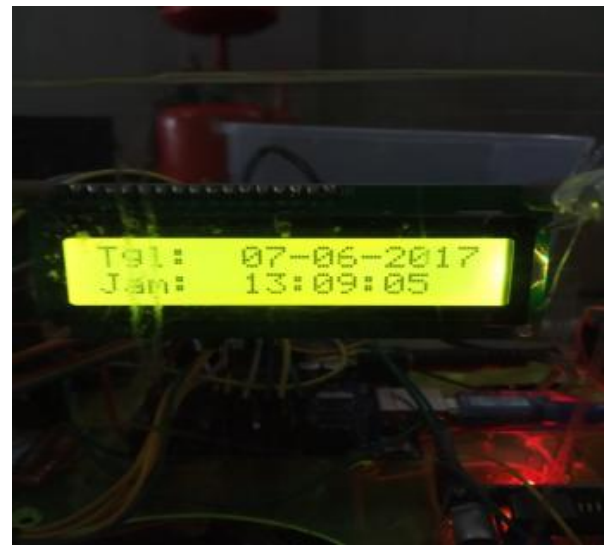

Gambar 8. Waktu Penyiraman

Berikut gambaran pada saat pompa air aktif dan melakukan penyiraman yang dapat dilihat pada gambar 8 dibawah ini :

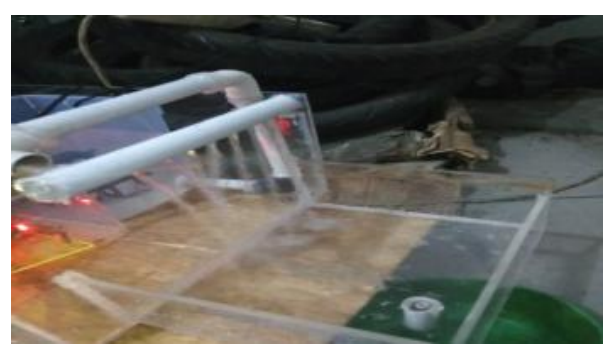

Gambar 9. Pompa Air Aktif

Berikut gambaran SMS yang masuk kepada nomor ponsel yang telah didaftarkan pada saat pompa air aktif dan melakukan penyiraman yang dapat dilihat pada gambar 9 dibawah ini :

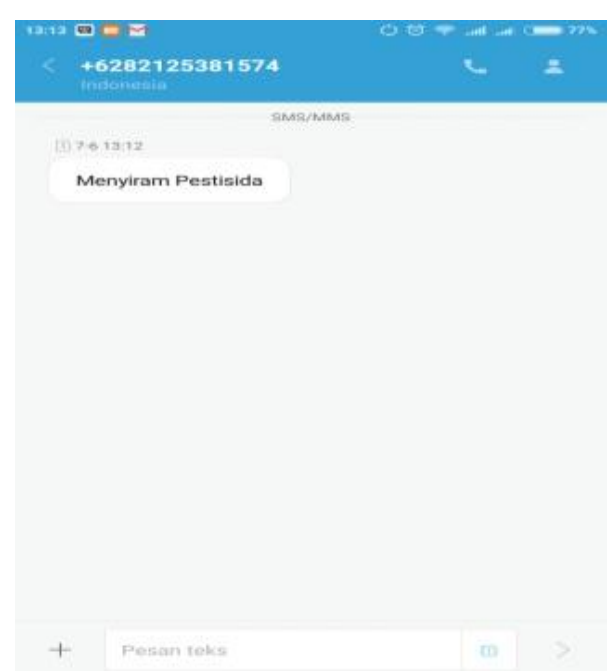

Gambar 10. Pesan Masuk Pada Smartphone
Apabila waktu sudah melebihi dari waktu yang diset maka pompa akan berhenti melakukan penyiraman contoh jam 13-10 disini waktu sudah lewat 1 menit menandakan waktu penyiraman sudah selesai. Berikut adalah gambar saat pompa telah selesai melakukan penyiraman dapat dilihat pada gambar 10 dibawah ini :

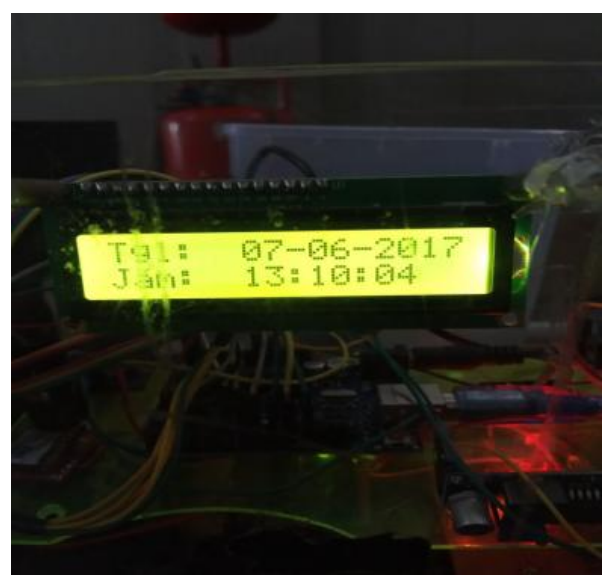

Gambar 11. Waktu Pompa Mati

Berikut gambaran pada saat pompa air mati dan menghentikan penyiraman yang dapat dilihat pada gambar 11 dibawah ini :

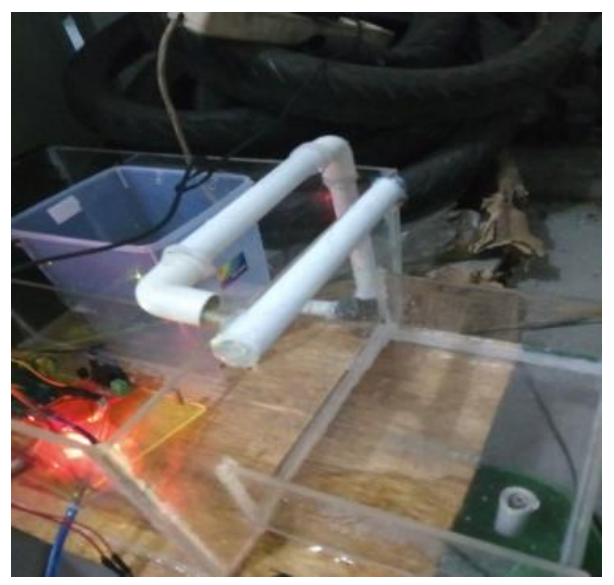

Gambar 12. Kondisi Pompa Mati

Berikut gambaran SMS yang masuk kepada nomor ponsel yang telah didaftarkan pada saat pompa air mati dan menghentikan penyiraman yang dapat dilihat pada gambar 12 dibawah ini : 
IN F ORMA T I K A

Jurnal Informatika, Manajemen dan Komputer, Vol. 12, No. 2, Desember 2020

eISSN : 2580-3042

pISSN : 1979-0694

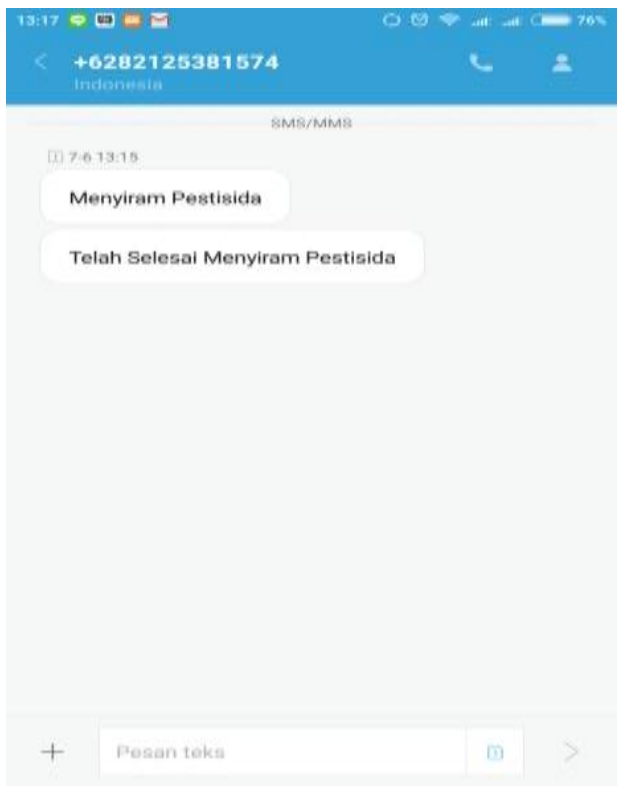

Gambar 13. SMS Masuk Pada Smartphone

Berikut adalah table hasil dari sistem pada penyiraman pestisida menggunakan arduino dan GSM Sheild dapat dilihat pada tabel 1 dibawah ini :

Table 1. Tabel Hasil dari Sistem

\begin{tabular}{|c|c|c|c|}
\hline $\begin{array}{c}\text { Kondisi } \\
\text { JAM }\end{array}$ & $\begin{array}{c}\text { Kondisi } \\
\text { Motor }\end{array}$ & Hasil SMS & LCD \\
\hline $\begin{array}{c}\text { Jika } \\
\text { Tanggal } \\
\text { 15-6-2020 } \\
\text { Jam 09 } \\
\text { Menit 19 }\end{array}$ & $\begin{array}{l}\text { Motor } \\
\text { Aktif }\end{array}$ & $\begin{array}{l}\text { Menyiram } \\
\text { Pestisida }\end{array}$ & $\begin{array}{c}\text { Jam dan } \\
\text { Tanggal } \\
\text { Tampil }\end{array}$ \\
\hline $\begin{array}{c}\text { Jika } \\
\text { Tanggal } \\
\text { 15-6-2020 } \\
\text { Jam 09 } \\
\text { Menit 20 }\end{array}$ & $\begin{array}{c}\text { Motor } \\
\text { Mati }\end{array}$ & $\begin{array}{c}\text { Telah Selesai } \\
\text { Menyiram } \\
\text { Pestisida }\end{array}$ & $\begin{array}{c}\text { Jam dan } \\
\text { Tanggal } \\
\text { Tampil }\end{array}$ \\
\hline $\begin{array}{c}\text { Jika } \\
\text { Tanggal } \\
29-6-2020 \\
\text { Jam 09 } \\
\text { Menit 19 }\end{array}$ & $\begin{array}{l}\text { Motor } \\
\text { Aktif }\end{array}$ & $\begin{array}{c}\text { Menyiram } \\
\text { Pestisida }\end{array}$ & $\begin{array}{c}\text { Jam dan } \\
\text { Tanggal } \\
\text { Tampil }\end{array}$ \\
\hline \begin{tabular}{|c|} 
Jika \\
Tanggal \\
29-6-2020 \\
Jam 09 \\
Menit 20
\end{tabular} & $\begin{array}{l}\text { Motor } \\
\text { Mati }\end{array}$ & $\begin{array}{c}\text { Telah Selesai } \\
\text { Menyiram } \\
\text { Pestisida }\end{array}$ & $\begin{array}{c}\text { Jam dan } \\
\text { Tanggal } \\
\text { Tampil }\end{array}$ \\
\hline \begin{tabular}{|c|} 
Jika \\
Tanggal \\
$15-7-2020$ \\
Jam 09 \\
Menit 19 \\
\end{tabular} & $\begin{array}{l}\text { Motor } \\
\text { Aktif }\end{array}$ & $\begin{array}{l}\text { Menyiram } \\
\text { Pestisida }\end{array}$ & $\begin{array}{c}\text { Jam dan } \\
\text { Tanggal } \\
\text { Tampil }\end{array}$ \\
\hline
\end{tabular}

\begin{tabular}{|c|c|c|c|}
\hline $\begin{array}{c}\text { Kondisi } \\
\text { JAM }\end{array}$ & $\begin{array}{c}\text { Kondisi } \\
\text { Motor }\end{array}$ & Hasil SMS & LCD \\
\hline $\begin{array}{c}\text { Jika } \\
\text { Tanggal } \\
\text { 15-7-2020 } \\
\text { Jam 09 } \\
\text { Menit 20 }\end{array}$ & $\begin{array}{c}\text { Motor } \\
\text { Mati }\end{array}$ & $\begin{array}{c}\text { Telah Selesai } \\
\text { Menyiram } \\
\text { Pestisida }\end{array}$ & $\begin{array}{c}\text { Jam dan } \\
\text { Tanggal } \\
\text { Tampil }\end{array}$ \\
\hline Jika & & & Jam dan \\
Tanggal & Motor & Menyiram & Tanggal \\
29-7-2020 & Aktif & Pestisida & Tampil \\
Jam 09 & & & \\
Menit 19 & & & Jam dan \\
\hline Jika & & Manggal \\
Tanggal & Motor & Menyiram & Pampil \\
29-7-2020 & Mati & Pestisida & \\
Jam 09 & & & \\
Menit 20 & & &
\end{tabular}

Dari tabel hasil pengujian diatas terbukti sistem yang dibangun telah sesuai dengan rule yang diberikan. Jika kondisi jam telah menunjukkan sesuai dengan waktu yang telah ditetapkan maka pompa air akan menyala dan mengalirkan cairan peptisida untuk menyiram tanaman, serta motor akan mati secara otomatis sesuai dengan waktu yang telah ditentukan. Penerapan GSM Shield 800L dapat berfungsi dengan baik untuk melakukan pengiriman pesan kepada nomor hanphone yang telah di daftarkan pada sistem.

\section{KESIMPULAN}

Berikut kesimpulan yang di dapat dari pembahasan sebelumnya :

a. Untuk membuat tanaman menjadi lebih subur dan terbebas dari hama jahat dirancanglah sebuah alat penyiraman pestisida menggunakan arduino dan GSM Sheild dengan menggunakan RTC, alat ini dirancang agar dapat berkerja secara otomatis berdasarkan waktu yang sudah diset pada sistem.

b. Alat ini dibagun menggunakan alat-alat seperti Arduino UNO R3, RTC DS1307, GSM Shield Sim 800L dan LCD dimana keseluruhan alat tersebut dibagun menjadi suatu sistem yang dapat berkerja secara otomatis.

\section{REFERENSI}

Alam, S., Tony, H., \& Darmawan, I. G. A. (2018). Rancang Bangun Sistem Penyiraman Otomatis. Ejournal Kajian Teknik Elektro, 3(1), 44-57. 
Bahrin. (2017). Sistem Kontrol Penerangan Menggunakan Arduino Uno Pada Universitas Ichsan Gorontalo. Ilkom Jurnal Ilmiah, 9, 282-289.

Fajriani, G. N., Fadhilla, F. R., Hutagaol, R. R., Tinggi, S., \& Kesehatan, I. (N.D.). Hubungan Intensitas Penyemprotan Pestisida. 7(1), 66-76.

Fauzy, F., Mahyuddin, M., \& Lahna, K. (2017). Pemanfaatan Module Gsm ( Sim 900 ) Berbasis Arduino-Uno Sebagai Sistem Alarm Dan Pengunci Pintu Otomatis Jarak Jauh Utilization Of Gsm Module ( Sim 900 ) Based Arduino-Uno For Alarm System And Remote Automatic Door Locking. 7(1), 3538.

Hidayat, R. (2020). Rancang Bangun Prototype Drone Penyemprot Pestisida Untuk Pertanian Padi Secara Otomatis. Jurnal Mahasiswa Teknik Elektro, 3(2), 86-94.

Nurmansyah, N. (2016). Pengaruh Interval Aplikasi Dan Waktu Penyemprotan Pestisida Nabati Seraiwangi Terhadap Hama Helopeltis Antonii Pada Tanaman Kakao. Buletin Penelitian Tanaman Rempah Dan Obat, 25(1), 53.

Putra, I. M. P. W., Harsojuwono, B. A., \& Triani, I. G. . L. (2018). Terhadap Residu Profenofos Dan Karakteristik Mutu Sawi Pakcoy ( Brassica Rapa L ). Jurnal Rekayasa Dan Manajemen Agroindustri, 6(2), 158-168.

Udi, \& Firmansyah, Y. (2018). Penerapan Metode Sdlc Waterfall Dalam Pembuatan Sistem Informasi Akademik. Jurnal Teknologi \& Manajemen Informatika, 4(1), 184-191.

Yuniastuti, A. (2018). Hubungan Masa Kerja, Lama Menyemprot, Jenis Pestisida, Penggunaan Apd Dan Pengelolaan Pestisida Dengan Kejadian Keracunan Pada Petani Di Brebes. Public Health Perspective Journal, 2(2), 117-123. 